\title{
Challenges for Innovation and Sustainable Development in Latin America: The Significance of Institutions and Human Capital
}

\author{
Laura Zapata-Cantu ${ }^{1, *}$ and Fernando González ${ }^{2}$ \\ 1 EGADE Business School, Tecnológico de Monterrey, San Pedro Garza García 66269, Mexico \\ 2 Ductor Consultores SC, Monterrey 32070, Mexico; gonzalezf@ductorsc.com \\ * Correspondence: laura.zapata@tec.mx
}

check for

updates

Citation: Zapata-Cantu, L.; González, F. Challenges for Innovation and Sustainable Development in Latin America: The Significance of Institutions and Human Capital. Sustainability 2021, 13, 4077. https://doi.org/10.3390/ su13074077

Academic Editors: Phoebe Koundouri and Pantelis C. Kostis

Received: 14 February 2021

Accepted: 31 March 2021

Published: 6 April 2021

Publisher's Note: MDPI stays neutral with regard to jurisdictional claims in published maps and institutional affiliations.

Copyright: (C) 2021 by the authors Licensee MDPI, Basel, Switzerland. This article is an open access article distributed under the terms and conditions of the Creative Commons Attribution (CC BY) license (https:/ / creativecommons.org/licenses/by/ $4.0 /)$.

\begin{abstract}
Sustainable development is considered as one of the vital challenges of the 21st century for humanity. The COVID-19 pandemic has disrupted economic and social life, forcing governments and businesses to reconsider their priorities. There are rare empirical studies on the national innovation system and its relationship to sustainability development for emerging countries. This paper aims at shedding light on how mission-oriented policies have marked sustainable regional development and innovation in Latin America. The present study presents the capabilities that could support the improvement of the national innovation system and, as a consequence, sustainability development. To understand how Latin American countries act on innovation and sustainable development initiatives, two global rankings in these areas, The Global Innovation Index 2020 and The Sustainable Development Report 2020, were analyzed. The results indicate some obstacles must be overcome such as the high levels of social inequality and poverty that still constitute significant challenges for this region. Today's biggest challenges are facing a pandemic situation and guaranteeing economic development that allows the underprivileged to escape poverty without dooming future generations to an even more degraded environment than the current one. Innovation continues to play a critical role in the transition toward a more sustainable world.
\end{abstract}

Keywords: mission-oriented policies; dynamic capabilities; sustainable development; innovation Latin America

\section{Introduction}

Sustainable development is considered one of the vital challenges of the 21st century for humanity. In the words of Antonio Gutierres, the United Nations Secretary-General "climate change is the defining crisis of our time, and it is happening even more quickly than we feared" [1]. In this context, the 2030 Agenda with its 17 Sustainable Development Goals (SDGs), focused on prosperity, people, planet, peace, and partnerships, has become a key priority for governments and stakeholders including civil society, science, and business organizations. A radical transformation in governmental policies and business practices has been required to ensure the achievement of the goals.

The concern for sustainable development has been present on the world agenda since the early seventies, when the "Club of Rome", an international group of businessmen and scientists, and a Massachusetts Institute of Technology research team published "The Limits to Growth" [2]. This book presents the key factors that could have a decisive impact on world sustainability and the systemic interactions that could ultimately limit growth and negatively impact future generations. This study opened the debate on the effects of population growth on the natural environment, industrial pollution, use of nonrenewable resources, and agricultural production. The report brought new ideas, analysis, and questioning of the means and ends of growth and consumption of humanity, and its proposal was recognized by some and criticized by others. Still, in the end, it has become one of the cornerstones of sustainable development thinking. 
In 1972, the United Nations started playing a vital role in the sustainable development movement. The first Earth Summit was held in Stockholm, whose objective was to engage world leaders in discussing the critical challenges that humanity faces in terms of environmental pollution, identifying solutions, and setting specific goals. After that initial Summit, the UN assumed a more decisive leadership on the direction of the sustainability initiatives and encouraged governments to adopt formal commitments to protect the environment. In 1992, during the Rio de Janeiro Earth Summit, the participants defined Agenda 21, an outline for member countries on economic growth, social equity, and environmental protection that would support cooperation and development in the 21st century.

Subsequent summits have reinforced the commitments assumed by many countries, like the Kyoto Protocol in 1997, which focused on emissions control. The Millennium Summit in 2000 sought the commitment of UN member nations to a new global partnership to reduce extreme poverty and decrease environmental impact. At this Summit, concrete actions to be accomplished by 2015 became the Millennial Goals. In 2015, the Paris Agreement allowed for several commitments to be reinforced such as reducing global warming through the greenhouse effect. Subsequently, in this same year, the United Nations stated 17 Sustainable Development Goals (SDGs) to be achieved by 2030. These goals represent a call to action to address the negative impacts of economic development on society and the planet.

However, another crisis of our time has unexpectedly come from exogenous factors, COVID0-19. This pandemic has disrupted all economic and social life. This emergency has forced governments and businesses to reconsider their priorities in 2020 as the socioeconomic impacts of the pandemic globally have been of enormous proportions. Hence, a question arises, will sustainable development still be in the plan of governments and business in a world disrupted by this crisis?

The pandemic has collapsed, in the short-term, the resources of governments and businesses, and their priorities have suddenly changed to respond to the crisis. However, regardless of the circumstances, there is a consensus in government and industry that sustainable development will be a central item in their agendas in a post-pandemic world. As the UN in its report on COVID-19 states: "Leveraging this moment of crisis when usual policies and social norms have been disrupted, bold steps can steer the world back on track towards the Sustainable Development Goal" [3]. In the Sustainable Development Report 2020, Jeffrey Sachs says “The Sustainable Development Goals are needed more than ever. Their bedrock principles of social inclusion, universal access to public services, and global cooperation are the guideposts for fighting COVID-19 as well as for the investment-led recovery the world should adopt to overcome the economic crisis caused by the pandemic" [4].

Governments and companies that are characterized by their boldness in their commitment to the planet and society have included an innovative approach to their sustainable development initiatives. As Mazzucato mentions, sustainable development challenges create concrete problems that drive innovation across multiple sectors and actors [5]. This approach creates products and services that drive new business models that transform existing technologies and value chains.

Before the pandemic, a culture of boldness and innovation characterized those organizations that have assumed a strong commitment to sustainable development. In the post pandemic world, this culture will become critical to address the new challenges in the new era; as Henderson argues: "the crisis offers an opportunity for regeneration and fresh thinking: the capacity to innovate and re-imagine building new products and services that create wealth without negative externalities" [6].

As we have emphasized, innovation plays an essential role in the transition toward a more sustainable world, and there is a growing body of innovation studies that discuss how innovation policy can make a difference in this respect by employing concepts such as eco-innovation policy [7], transformative innovation policy [8], or mission-oriented innovation policy $[9,10]$. 
In Latin America, studies on innovation have mainly focused on the social and economic approach to development. For years, the conception of regional growth has relied on social and economic development, mostly achieved through institutional policies. Along this line of thought, innovation is a business activity and secondary for the region's growth [11]. For instance, Latin America's contribution to the world's innovative activity (measured through registered patents, which is a classical indicator for firms' innovation output) is marginal [12].

Countries in Latin America and the Caribbean face the challenge of finding new growth engines that allow them to achieve and sustain high economic and social development levels in the long term [13]. The need-and some solutions-for a more vital link between science and policymaking around sustainability has been previously addressed as a relevant aim worth taking up precisely at the regional level. We expect that such an analytical frame could provide policymakers-and any other actor playing a role at the regional level-with a tool that makes sense of the governance environment and sets prioritized courses of action vis-à-vis innovation and sustainability [14].

In this regard, this paper aims at shedding light on how dynamic capabilities and mission-oriented policies' theoretical perspectives would mark critical factors to support innovation and sustainable regional development and in Latin America. Specifically, as a first attempt to induce more insights from both perspectives as a theoretical framework of this phenomenon, this study addresses the following research questions: What types of challenges are nations facing for innovation and sustainable development? How do Latin American countries face these challenges in a dynamic and uncertain environment?

The paper contributes to various discussions. First, it presents the status of innovation and sustainable development in Latin American, a specific region where emergent economies converge. Second, it provides a review of dynamic capabilities at a macro level, focusing on their embedded essence of adapting and transforming to support, in this case, innovation and sustainable development processes. Third, it discusses mission-oriented policies and institutions' relevance to ensure economic growth based on innovation and sustainable development in Latin America. It adds to the fields of innovation and sustainability in Latin America, narrowing its scope of interest to the regional level, and the relevance to study one single phenomenon of innovation and sustainable development in Latin America from two theoretical perspectives: dynamic capabilities and mission-oriented policies.

\section{Innovation and Sustainable Development in Latin America}

Since the end of World War II to the present, the Latin American region has experienced a long period of political instability characterized by a high degree of corruption. This condition of uncertainty and insecurity has had an impact on the results of institutional indicators of innovation and sustainable development. Different strategies have been tried to respond to this reality: Latin America's problems are being circumvented by replicating the macro-level social and development policies of the developed countries, regardless of whether or not innovation has been adapted to the local micro reality [11].

During the last two decades, many Latin American economies have undertaken extensive institutional changes and economic reforms-privatizations, trade liberalization, financial and macroeconomic stabilization-intended to make domestic markets more open, competitive, and efficient [15]. By now, the context had changed dramatically. All emerging markets face slower growth and different sources of instability.

The dramatic end of the commodity super cycle also underlines the return of uncertainty to Latin America, though in a much more subtle form with inflation rates, debt, and currency stability deteriorating in several large economies. Politically, countries that rely the most on commodity exports suffer from the higher risk of instability, with Venezuela leading the ranking in uncertain business conditions [16]. At the end of 2020, China's recovery has again put pressure on the prices of commodities like copper, iron ore, and crude oil, which are key to the economic development of some of the countries of the region improving in the short-term the rate of growth, but increasing the risk of inflation and uncertainty. 
To reduce the uncertainty of a volatile environment, most countries implement public policies and devise strategies to stimulate their economies [17]. Argentina, Brazil, and Costa Rica have created Ministries of Science, Technology, and Innovation; Uruguay has created the Ministerial Cabinet for Innovation. Some countries have created special agencies like Brazil's Center for Strategic Studies and Management, combined with national science and technology plans and periodic information-gathering efforts on innovation activities. Combining these three areas seeks to bring greater coherence to policies [18].

Some Latin American countries have implemented national policies and strategies to build national innovation systems and sustainable development strategies. For instance, Argentina distinguishes core areas for sustainable development: the food industry, communication and technology, mining, tourism and forest conservation; ecotourism in Costa Rica; and wine, tourism, and aquaculture in Chile. Latin American governments have pointed out that the solution to the ecological problem does not consist of decreasing economic growth; instead, they argue that the answer to this problem is to provide ways to modify the unequal distribution of authority and wealth across the entire world [19].

Latin American countries will continue to face nutrition and sanitary programs, poverty, quality education, and economic modernization. In such a context, leveraging innovation opportunities will become a crucial factor in determining their success $[17,18]$.

\subsection{Innovation in Latin America}

Innovation is the engine of economic growth. It is innovation and its diffusion within and across national boundaries - rather than capital accumulation - that explains countries' economic growth rates [20]. Despite the many initiatives to boost innovation in Latin America, the region contributes only marginally to the innovation activities worldwide. Even though the social benefits of innovation are usually wide-ranging, many companies are hesitant to initiate innovation because of the uncertainty involved [18].

Schumpeter, who saw the process of innovation as the engine of economic growth, postulates "without innovations, no entrepreneurs; without entrepreneurial achievement, no capitalist returns and no capitalist propulsion" [21]. The focus was, just as in some of the more recent work on sustainability, not on economic growth per se, but qualitative changes in the composition of output, the organization of economic activities, and the economy's structure [10]. In other words, successful exploitation of new ideas can lead to various forms of increased organizational or social benefit.

Innovation could be defined as everything a company does to sustain or gain market share over time. Thus, it is a process that depends on the ability to access and combine several different factors such as knowledge, skills, finance, institutions, and routines [10] that somehow need to be arranged and coordinated to allow the firm to function, profit, and thrive over time. Otherwise, it would perish, and companies as well as countries would fail to develop [11].

In Schumpeter's studies, the starting point is that today's innovation is highly dependent on the interplay between the external environment, economic, political, and governmental conditions as well as the internal, business configuration, resources, capabilities, and financial support. It is a coin of two sides that it is needed to allow innovation significance for economic growth.

Even though Latin America has a long tradition of science and technology development policies, the region is not finding it easy to reverse its deficit in this area by strengthening innovation policy. This deficit is because the countries making up the region face several challenges such as poor coordination between firms, high levels of corruption, shortages of skilled labor, and the limited ability of governments to act, which reduces the effectiveness of policy implementation [18].

Innovation policy is necessary with policies (and policy instruments) that influence innovation in a non-trivial manner, since what matters in achieving real progress concerning the transition to sustainability is a policy's impact, and not its label [10]. In this regard, the concept of sustainable innovation becomes relevant because innovations, as the 
renewal or improvement of products, services, technological, or organizational processes, offer better economic performance and enhance environmental and social performance. Furthermore, in both the short- and long-term can generate positive social and ecological impacts [22].

\subsection{Sustainable Development in Latin America}

Due to commitments generated by global initiatives such as the UN Sustainable Development Goals and the Paris Agreement, incorporating the concept of sustainable development into government agendas is currently a significant priority worldwide. According to the World Commission on Environment and Development, sustainable development is not a static situation, but a process in which resources are exploited, investments are managed, and technological and institutional development is directed in ways that are consistent with the present's future needs. Fundamentally, sustainable development is dependent on political will [23].

There are inherent tensions in regional development between economic growth, social inequality, and environmental sustainability, and these tensions coexist as paradoxical forces of regional development processes. We assume that such pressures give rise to challenges of governance for innovation and sustainable regional development.

For emerging countries, especially in the Latin American region, there are rare empirical studies on the national innovation system and its relationship to sustainability development. Innovation must play a crucial role in the transition toward sustainability. Still, it is much more challenging to provide useful models for how a policy may mobilize innovation for this purpose [24]. Nevertheless, there is extended literature using insights from innovation studies and how innovation policy can make a difference by employing concepts such as eco-innovation policy [9], transformative innovation policy [8], or mission-oriented innovation policy [7].

Despite the many initiatives to boost Latin American innovation, the region contributes only marginally to the innovation activities worldwide [18]. The developing economies must stop relying on imported technologies to solve their problems. In this regard, to increase a nation's productivity, it is necessary to innovate [12]. Experiences around the world demonstrate that the establishment of reliable innovation ecosystems based on companies, universities, and support institutions, among others, generate virtuous circles throughout society [11].

The present study presents the capabilities that could add value to the improvement of the national innovation system and, as a consequence, in sustainable development initiatives characterized by their innovative approach. This study's core issue - the relationship of the national innovation system and sustainability development—should be particularly salient in this study context and offer great practical relevance for specific Latin American countries whose cultural profiles are similar. Two crucial questions arise:

1. How innovation could be explained as a crucial activity for an approach to sustainable development based on dynamic capabilities in Latin America? The dynamic capability view (DCV) has become one of the leading frameworks to identify long-term survival and country growth drivers. As innovation and sustainable development are those drivers, understanding the capabilities required become critical.

2. Additional to dynamic capabilities, have mission-oriented policies become a critical success factor in this crusade? It seems that Latin American countries need to include policies that support and intensify innovation and sustainability for the next decade in their long-term mission statements.

\section{Dynamic Capabilities from a Macro Level}

The dynamic capability theory of economic growth assigns the central role in economic development to firms and a vital role to governments. The rate at which a country's economy grows critically depends on whether its firms can build the capabilities to generate and take advantage of "windows of opportunity" that exist for innovation, new markets, 
and enhance their capabilities to move into higher value-added activities [20]. In recent years, several scholars have paid attention to the ability and need for public policy to help firms create new markets and support the wider "industrial commons" that by their very nature can be seen as a "public good". Pitelis and colleagues have gone further in proposing that the nature and essence of the firm is not in terms of being a solution to market failures, but rather as a means for market and business ecosystem creation and co-creation [25]. Public, private, and social activities need to occur. The most critical is that the three dynamic capabilities (DCs) are required to come out to anticipate, sense, seize and transform resources and capabilities to respond to market changes and needs $[25,26]$.

The DCV, as it is generally espoused in the literature, is aimed at understanding processes relating to sensing the firm's resource bases to achieve shaping and seizing opportunities and reconfiguring the something that has been coined 'fitness' organizational survival and growth [27]. According to Teece, the focus of dynamic capabilities is identifying opportunities by scanning, searching, and exploring across technologies and markets to address the rapidly changing environment and to match market changes [28-30].

One major source of confusion identified in the literature is the question of the level at which DCs reside. More specifically, DCs are essentially a multilevel phenomenon spanning individuals, groups, business units, organizations, and alliances, and that much of the definitional confusion arises from a failure to account for the interactions across levels and between contexts. In a macro-level analysis, market creation and co-creation is the dynamic capability par excellence, the mother of all dynamic capabilities [25]. For instance, governmental capability is the ability to anticipate and influence change, guide future actions (i.e., sensing), make informed, intelligent decisions about policy; develop programs to implement policy (i.e., seizing); attract and absorb resources; manage resources; and evaluate current activities (i.e., configuring).

The long-term sustainability of a business ecosystem depends on how strong its dynamic capabilities are. Dynamic capabilities are the capacity (1) to sense and shape opportunities and threats, (2) to seize opportunities, and (3) to maintain competitiveness through enhancing their capabilities [25].

To develop each of these capabilities for the macro level, sense and shape opportunities and threats are the first set of dynamic capabilities [28]. This refers to recognizing the global megatrends and market opportunities that are relevant to the nation that are required to match the changing environment. Sensing new opportunities refers to scanning, creation, learning, and interpretive activity, both 'local' and 'distant'. This activity involves investment in research activity, the probing and reprobing of customer needs and technological possibilities, and understanding the latent demand, the structural evolution of industries and markets, and likely supplier and competitor response. This capability also considers the relevance to 'sensing' information about what is going on in the business ecosystem. The locus of world-class research/productive capability might lie external to the enterprise, so that the ability to procure technology externally as well as develop it internally are critical skills to compete [28].

Moreover, seizing opportunities for a country requires a systematic approach to mission-oriented strategies and the combination of technological market and knowledge, human capital development and continuous learning. Seizing the opportunities for a new country mission involves improving technological competences and complementary assets to facilitate strategic and investment decisions in technologies and designs most likely to achieve marketplace acceptance and are aligned to the mission. Here, it is important to use resources in a balanced manner and collaborate with people who can bring new perspectives and complement existing knowledge. The capacity of an enterprise to create, adjust, hone, and, if necessary, replace business models is foundational to dynamic capabilities [28].

Reconfiguring or transforming capabilities to maintain competitiveness requires building new competences and implementing new strategies. The combination of know-how between the enterprise and external organizations such as firms, universities, and research 
centers is important. Integrating know-how from outside as well as within the enterprise is especially important to success when 'systems' and 'networks' are present [28].

\section{Dynamic Capabilities for Innovation and Sustainable Development}

The nature of innovation and sustainable development is dynamic, complex, and characterized by constant and unpredictable change. Its guidelines and institutional approaches are often ambiguous [31]. In this regard, their success requires constant adjustments, which can be enabled by dynamic capabilities that allow a firm to integrate assets and resources, resulting in new resource configurations [29]. What should be highlighted is a tendency toward shifting emphasis from industrial process efficiency to a focus on sustainability that can be identified in the way that innovation policies have evolved in the Western world. There is a gradual shift from an initial focus on process quality toward a more complex understanding of excellence. A "public entrepreneur", a public-sector actor, can be critical in co-funding the required research, disseminating the knowledge needed by all firms and institutions to establish a presence in emerging ecosystems [28], and supporting dynamic capabilities to have an agile and opportunistic national and international response.

Innovation and sustainable development have become key drivers for the survival of firms and country growth. Dynamic capabilities become critical since they enable firms to monitor the emerging needs of various stakeholders, seize innovation and sustainable development opportunities from the rapidly changing stakeholders' expectations, and reconfigure existing functional capabilities for both processes [32].

The idea of dynamic capabilities in the public sector by merging the concept of the dynamic capabilities of the firm (from the Schumpeterian business administration literature and practice) was introduced by Kattel and Mazzucato with that of the capacities of the state [26]. For organizations, some of them already have a healthy level of dynamic capabilities and are in a better position to explore, exploit, and lead change. The government should develop dynamic capabilities that allow it to help create and co-create a supportive macroeconomic, institutional, and a business context that fosters the change process required by all stakeholders to commit to sustainable development.

A mission-oriented approach to innovation policy is a powerful systemic policy initiative that enables the public sector to promote the development of specific technologies that both shape the modern economy and contribute to the solution of economic, social, and environmental problems, which implies dynamic capabilities [33].

\section{Mission-Oriented Policies}

Different transformation periods have shaped the modern world. In the 16th and 17th centuries, it was the Age of Exploration; the Age of Reason in the 18th century, and the Space Age in the 20th century. These ages were driven by a sense of mission that responded to concrete challenges: expanding commerce and Western culture, structuring rational thinking to define objective truth, and more recently, the challenge of conquering space and putting a man on the Moon as a corner stone. These revolutions have brought structural changes and innovations that reshaped society, culture, technology, and science.

In the 21st century, humanity faces a new challenge that reflects accelerated global growth: sustainable development. The lack of response to this critical problem could impact climate change, the environment, the species, and eventually humankind. Without a doubt, we face a new "age" that will bring deep transformations in society, culture, and technology. This situation could be similar to the Moon shot or the Internet developing during the last decades of the past century. Mazzucato considers that this impressive task requires "like the Moon landing, the Internet, biotechnology, nanotechnology to be structured around mission-oriented policies that involve technological, behavioral, and systemic changes [5]" She also points out that mission-oriented policies emanated from the public sector, which focuses on society's solution-specific problems requiring the participation of different players to solve them. For instance, "the Moon landing 
project" by itself developed a web of partnerships between public and private sectors that advanced technological innovation in many fields. This project required advanced science, technologies, and innovative products and services that allowed for the development of new markets and, consequently, new business models [5].

To be future-oriented, it is essential to respond to the enormous challenge that represents changing the critical players' minds to have a strategic vision. A strategic vision and the commitment to transform are what innovation and sustainable development in Latin American countries require. Key players need to visualize sustainable development initiatives as an integral effort from both the public and private sectors. There is also a need to focus on a mission-oriented approach characterized by specific targets, collaboration between different sectors and players, innovative methods to execute, and new sustainable business models to have an impact on the sustainable development agenda.

A mission-oriented approach to innovation policy is a powerful systemic policy initiative that enables the public sector to promote the development of specific technologies that shape both the modern economy and contribute to the solution of economic, social, and environmental problems [13].

Fundamental changes must occur inside the organizations to capitalize on the opportunities generated by mission policies. For instance, an innovation culture becomes critical to align the firm with new environmental circumstances. This culture needs to develop new values, behaviors, climate, resources, capabilities, and processes [34]. Therefore, the business sector requires the move from a risk management approach to sustainable development to an approach focusing on seizing opportunities, a better understanding of the opportunities and challenges that an innovative approach to sustainable development can bring, and their impact on the current business model. In the case of the public sector, new capabilities development becomes a critical factor to be able to lead mission-oriented policies: "leadership and engagement, experimentation, coordination of different expertise become critical capabilities to lead change" [26].

In this regard, we consider that governments, like businesses, do not merely focus on solving market failures, like the negatives externalities of production processes that impact the environment. Still, they should also help create and co-create markets and wider ecosystems-also known as clusters-thereby co-creating the common ground within which public, private, and social activity occurs. Importantly, all three require dynamic capabilities (DCs) to anticipate, sense, seize, and transform to foster a comprehensive sustainable competitive advantage [25].

In this regard, as a first attempt to induce more insights from both perspectives as a theoretical framework of innovation and sustainable development phenomenon in Latin America, the following research questions emerge: What types of challenges are nations facing for innovation and sustainable development? How do Latin American countries face these challenges in a dynamic and uncertain environment?

This study analyzes the performance in innovation and the UN Sustainable Development Goals in 15 Latin American countries. We recognize how these countries respond to the challenges based on the dynamic capabilities of sensing, seizing, and transforming. Additionally, we identify how their initiatives in innovation and sustainability align with the mission-oriented policies. While the literature has emphasized the analysis of mission-oriented policies in developed countries, there are more opportunities in analyzing this phenomenon in developing countries because of the more significant challenges they face [26].

\section{Methods}

To understand how Latin American countries perform in innovation and sustainable development initiatives, two global rankings in these areas were analyzed: The Global Innovation Index 2020 and The Sustainable Development Report 2020 presented by United Nations and Cambridge University. The main objective was to assess how Latin American countries globally perform and identify which factors are the key enablers. The following 
analysis will provide insights into how Latin American countries face these challenges in an environment characterized by its dynamism and uncertainty.

\subsection{Innovation Initiatives}

In the first analysis, the Global Innovation Index 2020 was reviewed to identify the scores and rankings of Latin American countries in its seven dimensions regarding innovation input and output sub-indexes. For a more in-depth analysis, we identified the alignment of these seven dimensions with each of the three dynamic capabilities proposed by Teece [29]: sensing, seizing, and transforming (see Figure 1).
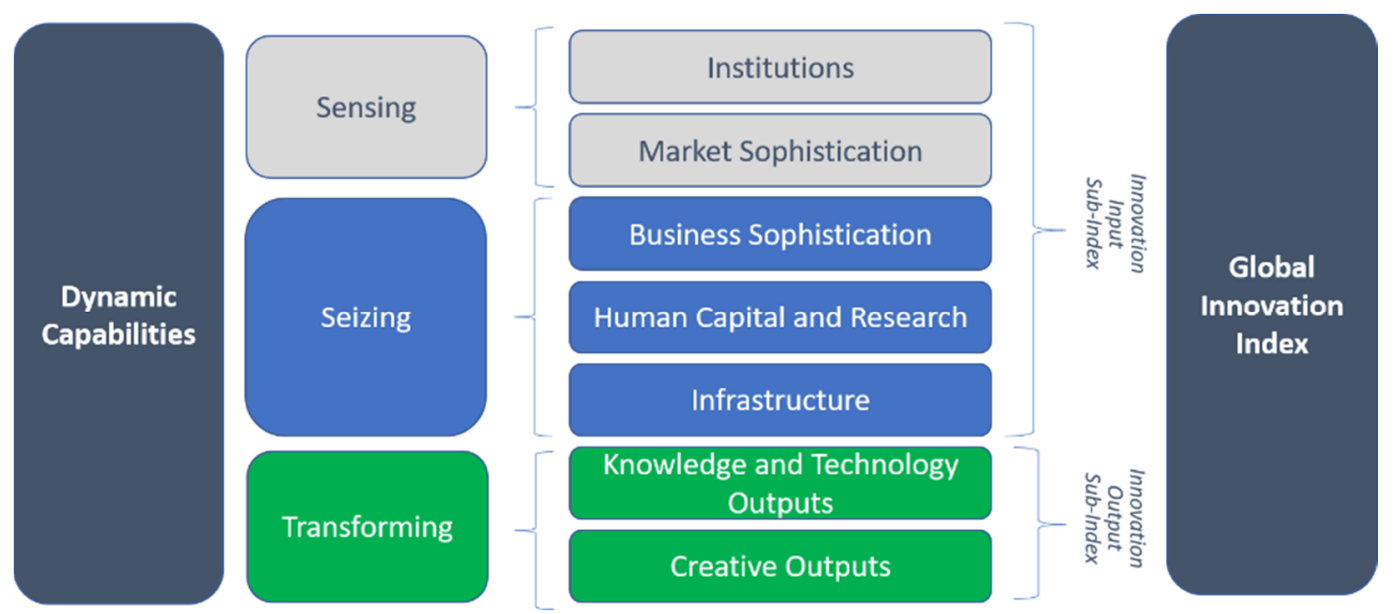

Figure 1. Dynamic capabilities and the Global Innovation Index alignment. Source: Own elaboration.

The Global Innovation Index comprises five innovation input dimensions that capture elements of the national economy that enable innovative activities [35]: institutions, market sophistication, business sophistication, human capital and research, and infrastructure. Each dimension is subdivided into three sub-dimensions. Two innovation outputs result from innovative activities within the economy: knowledge and technology outputs and creative outputs. Something important to highlight is that the overall global innovation index score is the average of the five input and two output dimensions. Table 1 presents the dimensions and sub-dimensions that comprise the Global Innovation Index.

In a first analysis, each dynamic capability is explained as being necessary to identify how the Global Innovation Index dimensions align with dynamic capabilities (see Table 1). The literature on dynamic capabilities points out that innovation is about much more than new products; it is about reinventing business processes and building entirely new markets that meet untapped customer demand [28]. Sensing and seizing capabilities allow business ecosystems to adapt to the market opportunities, and the management's ability to identify, develop, and utilize specialized and specialized assets built or bought, permitting the transformation and reshaping of organizations to respond to market needs.

Table 1 shows the alignment between dynamic capabilities and the Global Innovation Index dimensions, which could give insights into the capabilities that support innovation in Latin American countries. In this regard, sensing capability supports the identification of opportunities, recognizing the global megatrends and market opportunities relevant to the nation. This capability is highly relevant for institutions and market sophistication, reflecting its impact in financial support, competitive advantage, and market scale. Seizing dynamic capability refers to a systematic approach to combine technology, market, knowledge, and human capital development. In this regard, Global Innovation Index dimensions related to human capital and research consider education, research, and development as priorities. Infrastructure and business sophistication dimensions of knowledge workers and absorptive capacity allow an intelligent use of resources in a balanced manner as well as collaborating with other institutions and organizations. Finally, transforming capability 
indicates how the renewal of resource base and competences combining assets to enhance organizational value such as knowledge and technology outputs and creative outputs.

Table 1. Alignment dynamic capabilities and the Global Innovation Index dimensions.

\begin{tabular}{|c|c|}
\hline Dynamic Capabilities Definition & Global Innovation Index Dimensions \\
\hline \multirow{2}{*}{$\begin{array}{l}\text { Sensing } \\
\text { Identify opportunities } \\
\text { Processes to identify target market segments, changing customer needs, } \\
\text { and customer innovation. }\end{array}$} & $\begin{array}{l}\text { Institutions } \\
\text { Political environment } \\
\text { Regulatory environment } \\
\text { Business environment }\end{array}$ \\
\hline & $\begin{array}{l}\text { Market Sophistication } \\
\text { Credit } \\
\text { Investment } \\
\text { Trade, competition and market scale }\end{array}$ \\
\hline \multirow{3}{*}{$\begin{array}{l}\text { Seizing } \\
\text { Resources and capacities } \\
\text { Selecting enterprise boundaries to manage complements and "control" platforms. } \\
\text { Selecting the technology, designing revenue architectures, and designing } \\
\text { mechanisms to capture value. }\end{array}$} & $\begin{array}{l}\text { Human capital and research } \\
\text { Education } \\
\text { Tertiary education } \\
\text { Research and development }\end{array}$ \\
\hline & $\begin{array}{l}\text { Infrastructure } \\
\text { Information and communication technologies } \\
\text { General infrastructure } \\
\text { Ecological sustainability }\end{array}$ \\
\hline & $\begin{array}{l}\text { Business sophistication } \\
\text { Knowledge workers } \\
\text { Innovation linkages } \\
\text { Knowledge absorption }\end{array}$ \\
\hline \multirow{2}{*}{$\begin{array}{l}\text { Transforming } \\
\text { Combination, reconfiguration, and asset protection skills } \\
\text { Managing strategic fit so that asset combinations are value enhancing }\end{array}$} & $\begin{array}{l}\text { Knowledge and technology outputs } \\
\text { Knowledge creation } \\
\text { Knowledge impact } \\
\text { Knowledge diffusion }\end{array}$ \\
\hline & $\begin{array}{l}\text { Creative outputs } \\
\text { Intangible assets } \\
\text { Creative goods and services } \\
\text { Online creativity }\end{array}$ \\
\hline
\end{tabular}

Source: Own elaboration.

\subsection{Sustainable Development Initiatives}

The Sustainable Development Report 2020, presented by the United Nations and Cambridge University [4], was reviewed to obtain each Latin American country's score. In a first analysis, it identified the key sustainable development goals for each country. This analysis allowed us to determine the priorities of each country regarding sustainability. In a second analysis, we assessed the highest and lowest results for sustainable development goals from all countries. This cross-country analysis allowed us to identify the most remarkable aspects of this region, and those that need to improve their performance.

\section{Data Analysis and Results}

\subsection{Innovation Initiatives in Latin America}

Table 2 exposes the Global Innovation Index 2020 for 15 Latin American countries. Venezuela was removed from the outlook due to the difficulty of accurately measuring the entertainment and media market in that country and economic environment given its current political context. Nicaragua dropped from the GII economy sample due to data coverage being below the $66 \%$ threshold in the Output Sub-Index. 
Table 2. Global Innovation Index 2020, Latin American countries.

\begin{tabular}{|c|c|c|c|c|c|c|c|c|c|c|c|}
\hline \multirow[b]{2}{*}{ Country } & \multirow[b]{2}{*}{2020 GII } & \multicolumn{3}{|c|}{ Sensing } & \multicolumn{4}{|c|}{ Seizing } & \multicolumn{3}{|c|}{ Transforming } \\
\hline & & $\begin{array}{c}\text { Market } \\
\text { Sophistication }\end{array}$ & Institutions & Average & $\begin{array}{c}\text { Business } \\
\text { Sophistication }\end{array}$ & Infrastructure & $\begin{array}{l}\text { Human } \\
\text { Capital \& } \\
\text { Research }\end{array}$ & Average & $\begin{array}{c}\text { Knowledge \& } \\
\text { Technology } \\
\text { Outputs }\end{array}$ & $\begin{array}{l}\text { Creative } \\
\text { Outputs }\end{array}$ & Average \\
\hline Mexico & $33.60(55)$ & 59 & 74 & 67 & 59 & 59 & 58 & 59 & 55 & 54 & 55 \\
\hline Costa Rica & $33.51(56)$ & 89 & 66 & 78 & 48 & 62 & 66 & 59 & 53 & 53 & 53 \\
\hline Brazil & $31.84(62)$ & 91 & 82 & 87 & 35 & 61 & 49 & 48 & 56 & 77 & 67 \\
\hline Uruguay & $30.84(69)$ & 114 & 46 & 80 & 85 & 52 & 71 & 69 & 63 & 62 & 63 \\
\hline Colombia & $30.84(68)$ & 45 & 57 & 51 & 52 & 50 & 82 & 61 & 72 & 80 & 76 \\
\hline Peru & $28.79(76)$ & 38 & 72 & 55 & 43 & 68 & 57 & 56 & 112 & 87 & 100 \\
\hline Argentina & $28.33(80)$ & 120 & 97 & 109 & 61 & 70 & 48 & 60 & 75 & 71 & 73 \\
\hline Dominican Rep. & $25.10(90)$ & 105 & 98 & 102 & 83 & 77 & 100 & 87 & 99 & 82 & 91 \\
\hline El Salvador & $24.85(92)$ & 71 & 100 & 86 & 76 & 101 & 105 & 94 & 110 & 74 & 92 \\
\hline Paraguay & $24.14(97)$ & 93 & 109 & 101 & 84 & 89 & 98 & 90 & 115 & 78 & 97 \\
\hline Ecuador & 24.11 (99) & 64 & 126 & 95 & 97 & 82 & 91 & 90 & 105 & 92 & 99 \\
\hline Honduras & 22.95 (103) & 56 & 125 & 91 & 74 & 109 & 99 & 94 & 97 & 104 & 101 \\
\hline Bolivia & $22.41(105)$ & 78 & 129 & 104 & 90 & 104 & 56 & 83 & 114 & 109 & 112 \\
\hline Guatemala & $22.35(106)$ & 79 & 117 & 98 & 82 & 113 & 123 & 106 & 116 & 81 & 99 \\
\hline \multicolumn{2}{|c|}{ Average per dimension } & 75 & 86 & & 71 & 72 & 76 & & 85 & 76 & \\
\hline
\end{tabular}

Source: Own elaboration based on Global Innovation Index, 2020. Note: A lower indicator implies a better performance; a higher indicator indicates a worse assessment. 
In a general analysis of the dimensions that comprise the three dynamic capabilities among the 15 countries, business sophistication (71) was the dimension with a better assessment, follow by infrastructure (72), both included in the seizing capability. The institutions dimension, in sensing capability, had the lowest index (86). A significant aspect worthy of mention is that those countries with a better performance in the Global Innovation Index 2020 were characterized by a better score in the institutions dimension.

\subsubsection{Sensing Capabilities}

Latin American countries with a more favorable index in the Global Innovation Index are Chile and Colombia, showing that institutions and market sophistication are critical for these countries. Unlike countries with a lower Global Innovation Index in the ranking of Latin American countries such as Ecuador, Honduras, Bolivia, and Guatemala, the bestranked dimension was market sophistication (see Figure 2).

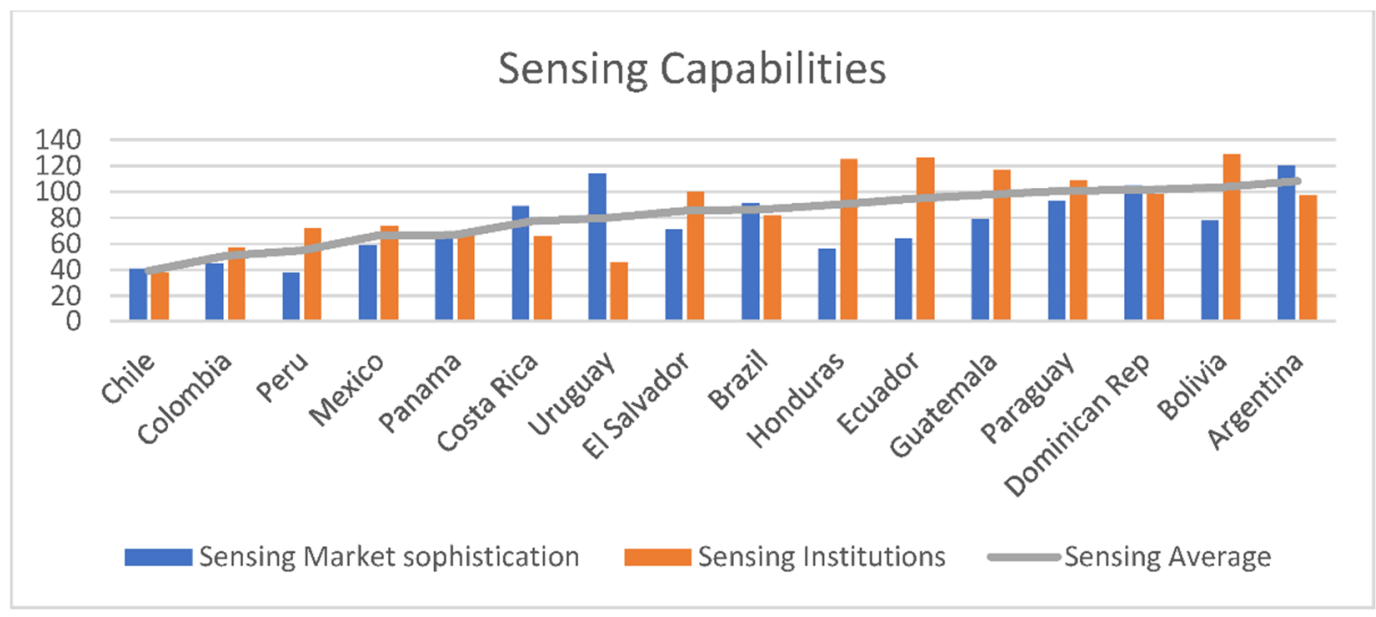

Figure 2. Sensing capabilities. Source: Own elaboration based on Global Innovation Index, 2020.

We can infer from this analysis that sensing is weak in Latin American countries by not considering both dimensions that explain sensing as keys to innovation: institutions and market sophistication. This finding is similar to the study by Aguilar-Barcelo and HigueraCota, who identified that the best performance in terms of overall technical efficiency was in the infrastructure pillar, while the worst performance was the institutional pillar, which revealed difficulties with the development of financial markets and with trade and competition [36]. There is a lack of an encouraging political, economic, and business environment and financial support to compete on a market scale.

\subsubsection{Seizing Capabilities}

Considering the Global Innovation Index dimensions that explain seizing capabilitybusiness sophistication, infrastructure, and human capital and research-only two Latin American countries ranked better in the Global Innovation Index: Chile and Brazil. For both countries in the top five rankings of Latin American countries, the business sophistication was translated as having human and research resources, the ability to assimilate new knowledge, build innovation bridges and infrastructure in general, and technology to innovate (see Figure 3). 


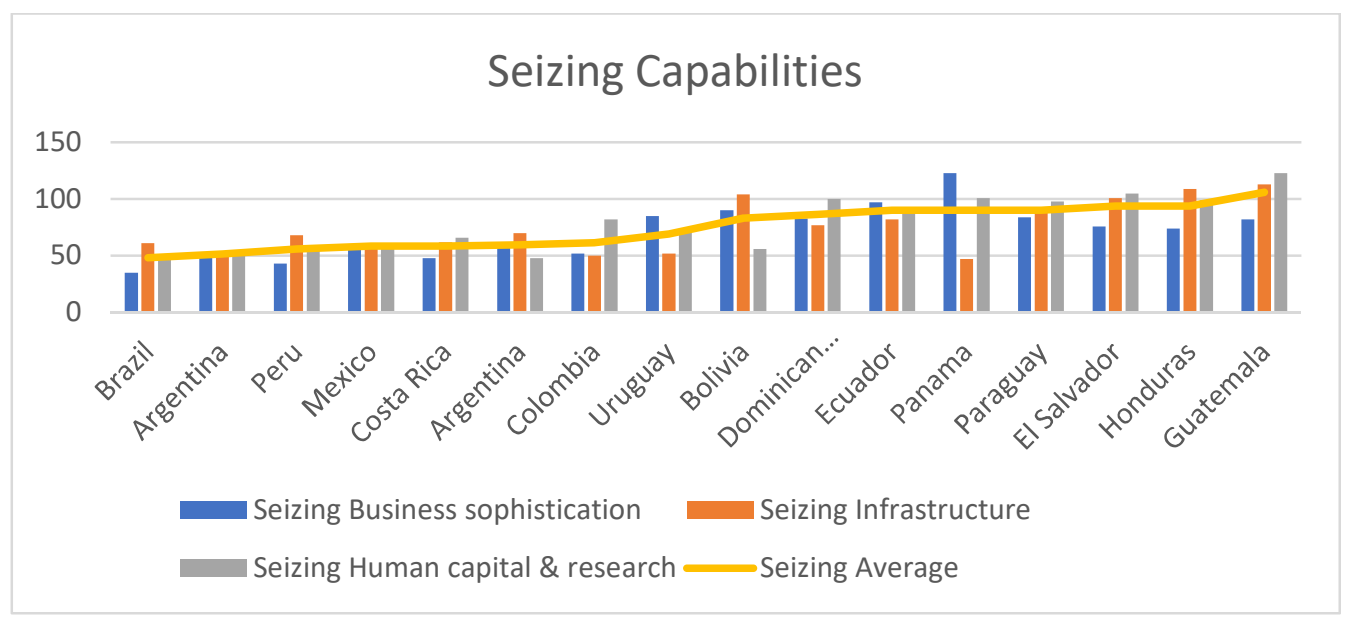

Figure 3. Seizing capabilities. Source: Own elaboration based on Global Innovation Index, 2020.

For the rest of the Latin American countries, business sophistication was better rated than infrastructure, human capital, and research. It can be inferred that these countries have knowledge workers, but they do not invest in human capital development, research, and infrastructure. A capability/market opportunity dynamic drives innovation. The government can support the creation of opportunities for firms by supporting scientific R\&D and technology development and helping firms build their capabilities through education and training policies [20].

Furthermore, human capital and technological capabilities are unevenly distributed among the economy's sectors and unevenly distributed among its cities and regions. To explain the countries' economic growth performance, we need to understand both the sectoral and the city and regional innovation systems that underpin them [20].

\subsubsection{Transforming Capabilities}

The transformation capacity is valued by two dimensions: knowledge and technology and creative outputs. The countries that stand out in this dimension are Costa Rica and Mexico, ranked third and second in the Global Innovation Index. The indices of sensing and seizing dimensions for these countries are not relevant, unlike the transforming capability, which indicates that there are countries in which companies have focused on reconfiguring their resources to innovate without considering sensing and seizing. It can infer that they innovate, but their processes or practices do not consider the environmental changes.

The dimensions with the highest score for the three dynamic capabilities, not well assessed in this ranking, but necessary for economic development are institutions, knowledge, and technology outputs (see Figure 4). There are apparent tensions and interrelationships between and amongst the three classes of dynamic capabilities identified in each country. In a study of six Latin American countries, [13] found the need to strengthen the public sector's institutional capacity to implement a mission-oriented approach from a sensing capability. Mission-oriented policies to innovate and, consequently, impel the country to achieve smart, inclusive, and sustainable long-term growth, are needed.

Governments can intervene to increase private investment in $R \& D$, investing in sectors considered crucial for economic development, or structuring policies that facilitate the creation of innovation-friendly environments [18]. Innovation is about generating high-technology products or increasing learning capabilities and involves seeking ways to maximize the use of technologies such as information and communication technologies [30]. 


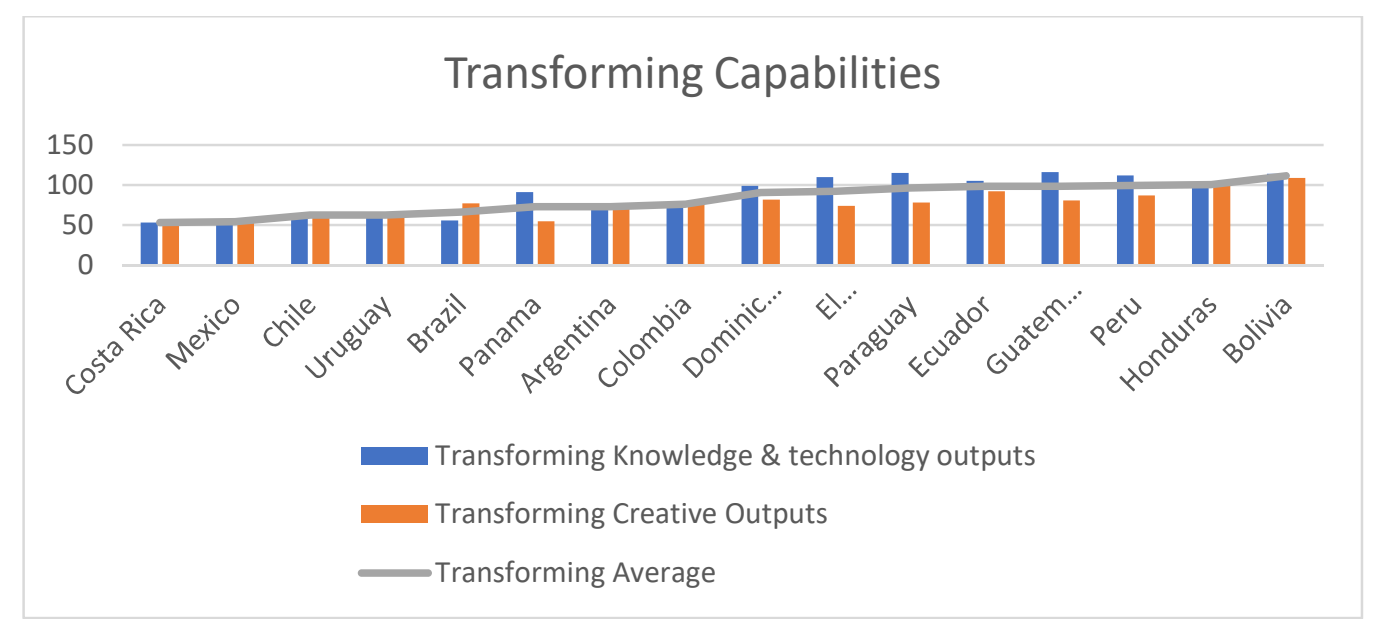

Figure 4. Transforming capabilities. Source: Own elaboration based on Global Innovation Index, 2020.

Governments recognize that innovation results from a set of conditions in various areas of public policy that must be articulated to produce the desired results. Nevertheless, Latin America needs to invest in R\&D to have an effective innovation and technology dissemination system. Brazil has made the most progress toward an integrated public innovation policy by creating sector funds and linking industrial policy to its innovation objectives. In most of the region, however, interventions in development, science and technology skills, and industrial policy are limited and compartmentalized [18].

The dynamic capabilities framework emphasizes the traits and processes needed to achieve a good position in a favorable ecosystem and explains new strategic considerations. It becomes necessary to ensure that businesses can seize opportunities, reconfigure their resources and capabilities when the market and technology are inevitably transformed once again and that there are public policies and institutions that support them $[26,28]$. The capability of the market opportunity dynamic that affects the firms' success or failure in a sector is the institutions of the country, where their critical operations are located. Institutions include laws, values, standards, and qualifications, which shape the agents' cognition and action and the interactions among them.

\subsection{Sustainable Development in Latin America}

The analysis of sustainability indicators was based on the 18 Latin American countries assessed in the United Nations Index (Table 3). In a comprised approach, the first analysis showed that almost all Latin American countries are in the middle portion of the sustainable development goals reported by the United Nations Index. Four countries can be highlighted: Chile (28), Costa Rica (35), Uruguay (45), and Ecuador (46), which are in the top 50 of 166 countries; the rest of the countries are positioned between places 51 to 120 .

The highest SDGs identified were SDG 13 'Climate action' in six countries; SDG 1 'No poverty' in seven countries; and SDG 4 'Quality education' in four countries. These results indicate that the socio-economic indicators are priority targets of the national strategy of Latin American countries as many countries displayed a positive trend of sustainable development of SDs 1 and 4. Additionally, environment indicators such as SDG 13 'Climate action' are becoming relevant in Ecuador, Brazil, Peru, El Salvador, Nicaragua, and Honduras.

However, some obstacles must be overcome such as the high levels of social inequality and poverty, which still constitute significant challenges for this region. The lowest-ranked SDGs were SDG 9 'Industry, innovation and infrastructure' in 10 countries and SDG 10 'Reduce inequality' in eight Latin American countries. The latter, SDG 10, shows that it is not addressed in almost all Latin American countries, with high inequality in this region. We must conclude that governments in this region do not identify imbalance as one of their 
key priorities [23]. It seems that while efforts have been made in these countries, there is still much work to do, especially in socioeconomic indicators such as SDG 9.

Table 3. Latin American countries in the United Nations Index.

\begin{tabular}{|c|c|c|c|}
\hline \multirow{2}{*}{ Country } & \multirow{2}{*}{2020 Index * } & \multicolumn{2}{|c|}{ ODS } \\
\hline & & Highest & Lowest \\
\hline Chile & $77.4(28)$ & 1 & 10 \\
\hline Costa Rica & $75.1(35)$ & 1 & 10 \\
\hline Uruguay & $74.3(45)$ & 1 & 9 \\
\hline Ecuador & $74.3(46)$ & 13 & 9 \\
\hline Argentina & $73.2(51)$ & $1 \& 4$ & 9 \\
\hline Brazil & $72.7(53)$ & $7 \& 13$ & 10 \\
\hline Cuba & $72.6(55)$ & 4 & 9 \\
\hline Peru & $71.8(61)$ & $4 \& 13$ & 9 \\
\hline Colombia & $70.9(67)$ & 7 & 10 \\
\hline Mexico & $70.4(69)$ & 4 & 10 \\
\hline Dominican Republic & $70.2(73)$ & 1 & 10 \\
\hline El Salvador & $69.6(77)$ & 13 & 9 \\
\hline Panama & $69.2(81)$ & $1 \& 11$ & 10 \\
\hline Nicaragua & $68.7(85)$ & 13 & 9 \\
\hline Paraguay & $67.7(90)$ & 1 & 9 \\
\hline Honduras & $64.4(105)$ & 13 & 9 \\
\hline Venezuela & $61.7(118)$ & 7 & 10 \\
\hline Guatemala & $61.5(120)$ & 13 & 9 \\
\hline
\end{tabular}

Source: Own elaboration based on United Nation Index, $2020 .{ }^{*}$ The first indicator is the score $(0-100)$, the number between parenthesis is the place in the ranking among all countries.

Chile, Costa Rica, and Uruguay are well assessed in both rankings. Their agendas are to simultaneously promote innovation while dealing more assertively with societal and environmental challenges. For instance, the Chilean strategy for the solar energy sector, set up by CORFO (the Chilean economic development agency) in 2016, aims to foster innovation, develop technologies and skills, and reduce carbon emissions, following a roadmap toward 2025 [13].

Costa Rica is also a country that deserves special mention as it spends nearly $0.6 \%$ of its GDP in R\&D. This trend started in 1997 with Intel's arrival. This technology company has had a strong influence on education, business practices, and the labor market in Costa Rica. For instance, more Costa Ricans are now graduating with degrees in highly skilled engineering or tech design and education curriculums include a greater emphasis on the sciences, maths, and technology [17].

\section{Discussion}

Today, Latin American countries face the most significant challenges: a pandemic situation that has disrupted the health systems and their economy and, at the same time, being able to guarantee economic development that allows the underprivileged to escape poverty without the risks that growth can bring of dooming future generations to an even more degraded environment than the current one. Additionally, as we have been emphasizing, innovation plays a critical role in the transition toward more sustainable development in the region. 
This study's main aim was to identify how innovation and sustainable development in Latin America need to be studied and analyzed as dynamic capabilities and, at the same time, visualized in the long-term supported by mission-oriented policies. For Latin American countries, it has become essential to respond with strategic vision and commitment from both the public and private sectors to face what innovation and sustainable development in Latin American countries require. The results show the need to analyze and strengthen to achieve economic growth in the region. Further efforts need to be made in institutions, human capital development, public policy plans, and investment in R\&D.

According to the World Commission on Environment and Development, sustainable development is not a static situation, but a process in which resources are exploited, investments are managed, and technological and institutional development is directed in ways consistent with the future needs of the present. Fundamentally, sustainable development is dependent on political will [23] and in the case of Latin American countries, institutions, and human capital development. The state plays a critical role in sustainable regional development. It will be relevant to generate mission-oriented policies that require strong institutional support.

Mazzucato points out that mission-oriented policies emanated from the public sector and focuses on society's solution-specific problems requiring the participation of different sectors to solve them [5]. It is not a one-way solution. Public, private, and social activity needs to occur; most critically, three dynamic capabilities (DCs) are needed to anticipate, sense, seize, and transform [25]. The present study shows that transforming is the only dynamic capability to innovation in the region, indicating that countries have focused on reconfiguring their resources to innovate without considering the environmental changes and seizing these changes with their resources. Regarding sustainable development in the region, the UN has defined the following challenges for Latin America: leaving no one behind, social inclusion, social protection, violence, citizen security, environmental climate change, and disaster risk management [4]. These six challenges are encompassed in two dimensions: social and ecological. By its nature, the answer to these challenges and the implementation of the UN Sustainable Development Goals 2030 requires a systemic approach, a nationwide effort coordinated by inclusive institutions and the business sector. This coordination has to define the laws and mission policies, motivate, reward, and create a positive environment for innovation and capability development. This approach has been a success in countries that have advanced better in implementing the SD Goals through innovation and dynamic capabilities.

The understanding of the institutional issues is typically more limited than the knowledge of the technologies themselves. This misinterpretation or understanding affords considerable scope for mistakes around the proper design of business models and the institutional structures needed to support innovation in the private and public sectors [28]. Vital institutions promote an inclusive approach to public and private players. They set the roadmap through mission-oriented policies that open opportunities for investment, innovation, and capabilities of new business organizations. The alignment of business organizations to mission-oriented guidelines create roadmaps that support organizational change to develop the culture and abilities required to implement innovative initiatives, so called "creative destruction," that adds value to the organization and its stakeholders.

National institutions guarantee the alignment of all players to mission-oriented policies since their executions require a move away from traditional ways of thinking and coordination. "Setting, financing, and monitoring a green growth agenda requires courage from all actors involved: to move away from traditional ways of thinking about climate change and innovation; to develop targeted, directed policies and protocols; and to start quickly with aspirational, achievable, and galvanizing missions" [37].

For instance, countries like Chile have worked to ensure long-term commitment to support innovation. It has improved the mechanisms for the allocation of resources and the governance structure of its institutions. At the same time, this country has developed institutions to drive innovation like the "Consejo Nacional de Ciencia, Tecnología, 
Conocimiento e Innovación", which provides knowledge in different fields to identify the opportunities to innovate products and services, and even traditional ways of doing things.

Aside from institutions, improving innovation in Latin America will require substantial investment in human resources development and in an overhaul of the public education system to reinforce the development of the basic skills required to innovate. The improvement of human skills must be accompanied by other policies to enhance the innovation and business environment including the modernization and expansion of infrastructure. It is fundamental that governments, firms, and universities jointly develop a research agenda that will identify significant issues and the effectiveness of solutions to foster innovation in the region. Innovation is a social process of public sector organizations that promote knowledge infrastructures such as universities and the government agencies that produce knowledge.

Public policy can help to encourage the improvement of the local pool of management talent. For example, programs that support education in advanced countries, periods of overseas employment, and eventual return to work at local firms can, over time, increase the quality level of the talent pool. In countries that already have several foreign subsidiaries, establishing programs with those who are willing to provide management training to local employees is another potential avenue to increase the stock of human capital [25].

There is no lack of talent, knowledge, and resources to succeed in a transformative innovation process [30]; the problem is how to mobilize these assets. Many firms are reluctant to move into new areas because they are uncertain about future results. One of the most effective instruments that policy-makers can use to remedy this problem is to influence the firms' expectations of the future, setting the direction [7]. Successful innovation depends on access and combining several different factors such as knowledge, skills, finance, institutions, and demand. Having access to knowledge, talent, and finance are extremely helpful [10].

The creation of a niche market turned out to be essential for developing the innovation (e.g., increasing performance and reducing costs through learning and economies of scale), so that it would eventually receive broader acceptance. There have been cases in Chile and Costa Rica that have bet on eco-tourism, flora, and fauna ecosystems for sustainable development and innovation. The creation and support of such niches have been recognized as useful tools by policy-makers that wish to support the development of a specific innovation (or innovations for a particular purpose) [10].

Support of niche-markets might be a possible way forward in sustainability transitions (e.g., strategic niche management, see [7]). However, mission-oriented policies (or strategic niche management) require competent policy-makers (or managers) and stringent procedures to avoid the many traps that such a project may easily fall into [10].

Figure 5 presents the proposed roadmap of the elements above-mentioned/that are crucial to aligning sustainable development to the mission-specific objectives: institutions, mission-oriented policies, dynamic capabilities, and a system innovation approach.

Business organizations operate in an environment where institutions play a crucial role in defining political, economic, social relations, and a country's strategic priorities. The stronger the institutions that guide the activities in the different sectors of the economy, the more precise each industry's strategic priorities will be, therefore, countries with weak institutions will find it more difficult to achieve specific answers to critical sustainable development problems. Strong institutions, in responding to critical 21st challenges like globalization, population growth, disruptive technologies, economic inequality, climate change, must establish mission-oriented policies that support a systemic alignment of the different players involved in their execution. 


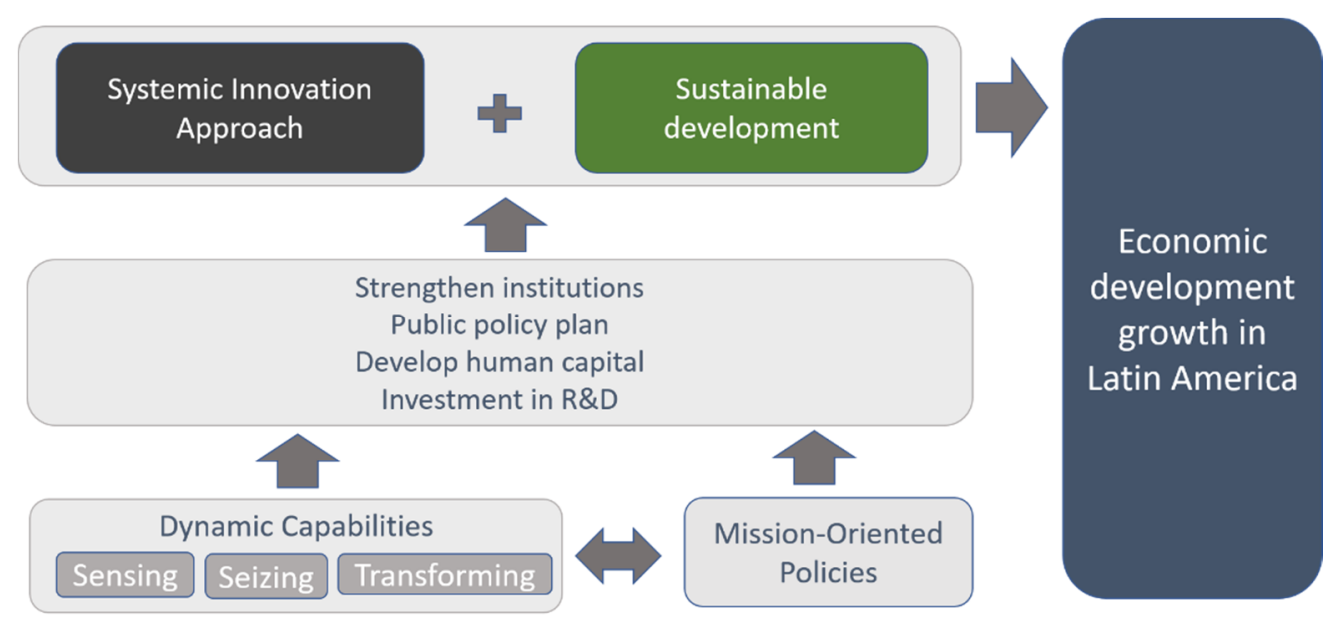

Figure 5. Roadmap for innovation and sustainable development alignment based on dynamic capabilities and missionoriented policies. Source: Own elaboration.

Sustainable development approached from a mission-oriented policies perspective allows business organizations to align their sustainable development strategies to the macro policies. These would enable profiting from the incentives that such policies could bring to business organizations that have succeeded in implementing sustainable development initiatives beyond simple compliance or risk management. Businesses have gone through change processes in their cultures supported by dynamic capabilities reflected in their innovation practices.

National innovation and sustainable development are changing processes that require frameworks, roadmaps, rules, incentives, and new opportunities. Institutions play a crucial role in directing and coordinating these efforts. Business organizations can define their roadmaps to implement the 2030 SD Goals, but if they do not consider that the change required "needs to be cross-sectoral, harnessing supply and demand, innovation and procurement, and public and private actors" [38], their efforts will be more focused on risk management initiatives to comply with the basics demanded by the laws or low impact initiatives that respond to the need to create a green image for the organization. The SD agenda demands changes. These changes require guidance from inclusive institutions that promote the value generation of the SD initiatives through mission-oriented policies that support innovation, dynamic capabilities, and new business models that add value to society and the environment.

Finally, a serious commitment to the 2030 Agenda demands business organizations not only to do better at what they already do but implement innovative approaches in their strategic initiatives. The scope of these innovative initiatives could take to business model innovation by integrating it in sustainable products and services that could respond to their value chain's needs. This approach could also redefine the business purpose by focusing on offering profitable solutions to the conditions created by the commitment to advance the 2030 Agenda. This approach adds value to people and the planet and builds trust and cooperation within society.

\section{Conclusions}

The dynamic capabilities framework emphasizes that the past will impact current and future performance. In this regard, Latin American countries need to shape their history and support their development with mission-oriented policies designed to tackle primarily societal challenges such as inequality, poverty, and youth unemployment. These challengesenvironmental, demographic, economic, or social—must enter innovation policy agendas as key justifications for action, providing strategic direction for funding policies and innovation efforts [13]. 
An economic development approach by doing more of the same will harm the achievement of the Sustainable Development Goals in countries and firms, emphasizing new economic development policies. These policies must encourage and support the rise in living standards and protect the environment, resource use, and society's improvement. The public sector needs to take an active and leading role in translating societal challenges into concrete missions, defining directions, and promoting the development and diffusion of relevant technologies necessary as part of an effective, smart, and innovation-led growth strategy [7].

The transition to sustainability not only requires innovations in the economy and innovations in institutions, but there is also a need for an innovation ecosystem confirmed by the top global universities, researchers, and firms. There must be a high-class governmental capability that could afford better coordination and policy alignment to achieve this. It can effectively fulfill its role of coordinating and providing direction to private actors when formulating and implementing policies that address societal challenges through innovation [7]. In this regard, it will be imperative to align the organization's business purpose to the mission-oriented policies.

Companies and countries must develop strategies to ensure innovation and compete in an uncertain environment. They need to create conditions, established through science and technology policy, infrastructure, and innovation ecosystems, to develop a sustainable and wealthy society $[11,22]$. Evoke Schumpeter's postulate: innovation is the engine of economic growth because of its role in increasing its production efficiency and competitive advantage [20].

Theoretical implications. Innovation and sustainable development in Latin America need to be studied from two essential theoretical frameworks: a dynamic capabilities framework and mission-oriented policies. The strengthening of both perspectives together will allow a significant achievement in regional development. Policy-makers and academics interested in this matter should know that the bidirectional relationship between innovation and per capita economic growth does not necessarily reflect the entire situation. More variables such as education and continuity of policies should also be studied [39].

Institutions and investment in basic education and human resource development are essential to innovation and, therefore, sustainable growth. The improvement in human skills must be accompanied by other policies to enhance the innovation and business environment including the modernization and expansion of infrastructure.

Political implications. The results reveal a set of interesting aspects regarding the determinants of innovation that are important for policy-making. The improvement skills must be accompanied by other policies to enhance the innovation and business environment including the modernization and expansion of infrastructure. Firms and their innovation capability enhancement should be at the core of any development policy.

It is also fundamental that governments, firms, and universities jointly develop a research agenda that will identify significant issues and the effectiveness of solutions to foster innovation in Latin America. A holistic approach is likely to help the country move up the value chain and become a knowledge economy. Innovation is seen as a social process of public sector organizations that promote knowledge infrastructures such as universities and the government agencies that produce knowledge. The institutional framework that arises from this understanding must outline an innovation ecosystem that allows economic agents to apply knowledge and develop new solutions, not only technological ones, within the region [11].

Implementing a mission-oriented approach to innovation policy requires developing dynamic capabilities, talent and expertise within the state, and very competent public agencies to learn from practice and use innovation policy proactively to support transformative innovation. Such capabilities cannot be taken for granted but need to be actively nurtured [10]. Still, governments are often uniquely positioned to mobilize and coordinate the numerous organizations needed to confront enormous innovation challenges [40]. 
It also requires governmental agencies responsible for the funding of S\&T (Science and Technology) and innovation projects need to develop assessment systems [39].

Limitations. The study's main limitation relies on the fact that only two international rankings were cross-sectional analyzed, and it is not possible to generalize the results. Future research efforts should be significant to analyze the indicators at specific countries regarding the dimensions under assessment and longitudinally analyze the countries that highlight innovation and sustainable development processes. Latin America remains the world's most unstable region. Reforms to strengthen education, research, and innovation must foster higher growth potential and higher productivity by improving workers' skills. They must also ensure equal opportunities in access to high-quality training. Missionoriented policies could drive the effective implementation of high impact initiatives. In the case of the UN Sustainable Development Goals, the creation of ecosystems that define the conditions for establishing a public plan encourages business organizations to explore and exploit innovation opportunities to create new products and services with low impacts on the environment and society [5]. In this regard, dynamic capabilities from a macro level and entrepreneurial management to sensing, understanding opportunities, and finding new and better ways of putting things together will allow for creatively coordination of specialized assembly elements, public and private teams, and stakeholders [28].

Author Contributions: Conceptualization, L.Z.-C. and F.G.; methodology, L.Z.-C.; formal analysis, L.Z.-C.; writing—original draft preparation, L.Z.-C. and F.G.; writing—review and editing, L.Z.-C. and F.G. All authors have read and agreed to the published version of the manuscript.

Funding: This research received no external funding.

Conflicts of Interest: The authors declare no conflict of interest.

\section{References}

1. United Nations. The Climate Crisis-A Race We Can Win. Available online: https://www.un.org/en/un75/climate-crisis-racewe-can-win (accessed on 7 December 2019).

2. Meadows, D. The Limits to Growth: A Report for the Club of Rome's Project on the Predicament of Mankind; Universe Books: New York, NY, USA, 1972.

3. United Nations. The Sustainable Development Goals: Our Framework for COVID-19. Available online: https://www.un.org/ sustainabledevelopment/sdgs-framework-for-covid-19-recovery (accessed on 24 November 2020).

4. Sachs, J.; Schmidt-Traub, G.; Kroll, C.; Lafortune, G.; Fuller, G.; Woelm, F. The Sustainable Development Goals and COVID-19. Sustainable Development Report 2020; Cambridge University Press: Cambridge, UK, 2020.

5. Mazzucato, M. Mission-oriented innovation policies: Challenges and opportunities. Ind. Corp. Chang. 2018, 27, 803-815. [CrossRef]

6. Henderson, D. Institutional work in the maintenance of regional innovation policy instruments: Evidence from Wales. Reg. Stud. 2020, 54, 429-439. [CrossRef]

7. Mazzucato, M. Mission-Oriented Innovation Policy: Challenges and Opportunities; UCL Institute for Innovation and Public Service: London, UK, 2017.

8. Steward, F. Transformative innovation policy to meet the challenge of climate change: Sociotechnical networks aligned with consumption and end-use as new transition arenas for a low-carbon society or green economy. Technol. Anal. Strat. Manag. 2012, 24, 331-343. [CrossRef]

9. Kemp, R.; Oltra, V. Research insights and challenges on eco-innovation dynamics. Ind. Innov. 2011, 18, 249-253. [CrossRef]

10. Fagerberg, J. Mobilizing innovation for sustainability transitions: A comment on transformative innovation policy. Res. Policy 2018, 47, 1568-1576. [CrossRef]

11. Zawislak, P.A.; Tello-Gamarra, J.; Fracasso, E.M.; Castellanos, O. Innovation beyond technology: Perspectives from Latin America. Acad. Rev. Latinoam. Adm. 2017, 30, 434-443. [CrossRef]

12. Ketelhöhn, N.; Ogliastri, E. Introduction: Innovation in Latin America. Acad. Rev. Latinoam. Adm. 2013, 26, 12-32. [CrossRef]

13. Mazzucato, M.; Penna, C.C.R. The Age of Missions: Addressing Societal Challenges through Mission-Oriented Innovation Policies in Latin America and the Caribbean; Interamerican Development Bank: Washington, DC, USA, 2020.

14. Balanzo, A.; Garavito, L.; Rojas, H.; Sobotova, L.; Pérez, O.; Guaquetá, D.; Sanabria, S. Typical Challenges of Governance for Sustainable Regional Development in Globalized Latin America: A Multidimensional Literature Review. Sustainability 2020, 12, 2702. [CrossRef]

15. Castellacci, F. Institutional voids or organizational resilience? Business groups, innovation, and market development in Latin America. World Dev. 2015, 70, 43-58. [CrossRef] 
16. Brenes, E.R.; Camacho, A.R.; Ciravegna, L.; Pichardo, C.A. Strategy and innovation in emerging economies after the end of the commodity boom-Insights from Latin America. J. Bus. Res. 2016, 69, 4363-4367. [CrossRef]

17. Olavarrieta, S.; Villena, M.G. Innovation and business research in Latin America: An overview. J. Bus. Res. 2014, 67, 489-497. [CrossRef]

18. Tadmor, D. The State of Innovation in Latin America. SSRN 2019. [CrossRef]

19. Toumi, O.; Le Gallo, J.; Rejeb, J.B. Assessment of Latin American sustainability. Renew. Sustain. Energy Rev. 2017, 78, 878-885. [CrossRef]

20. Sainsbury, D. Toward a dynamic capability theory of economic growth. Ind. Corp. Chang. 2020, 29, 1047-1065. [CrossRef]

21. Schumpeter, J.A. Business Cycles; McGraw-Hill: New York, NY, USA, 1939.

22. Cillo, V.; Petruzzelli, A.M.; Ardito, L.; Del Giudice, M. Understanding sustainable innovation: A systematic literature review. Corp. Soc. Responsib. Environ. Manag. 2019, 26, 1012-1025. [CrossRef]

23. Gambetta, N.; Azadian, P.; Hourcade, V.; Reyes, M.E. The financing framework for sustainable development in emerging economies: The case of Uruguay. Sustainability 2019, 11, 1059. [CrossRef]

24. Mowery, D.C.; Nelson, R.R.; Martin, B.R. Technology policy and global warming: Why new policy models are needed (or why putting new wine in old bottles won't work). Res. Policy 2010, 39, 1011-1023. [CrossRef]

25. Pitelis, C.N.; Teece, D. Dynamic Capabilities, Developmental Industrial Strategy and the Strategic SCA of Nations. SSRN 2016. [CrossRef]

26. Kattel, R.; Mazzucato, M. Mission-oriented innovation policy and dynamic capabilities in the public sector. Ind. Corp. Chang. 2018, 27, 787-801. [CrossRef]

27. Wilden, R.; Devinney, T.M.; Dowling, G.R. The Architecture of Dynamic Capability Research: Identifying the Building Blocks of a Configurational Approach. Acad. Mgmt. 2016, 10, 997-1076.

28. Teece, D.J. Explicating dynamic capabilities: The nature and microfoundations of (sustainable) enterprise performance. Strat. Manag. J. 2007, 28, 1319-1350. [CrossRef]

29. Teece, D.J. Business models, business strategy and innovation. Long Range Plan. 2010, 43, 172-194. [CrossRef]

30. Eisenhardt, K.M.; Martin, J.A. Dynamic capabilities: What are they? Str. Mgmt. J. 2000, 21, 1105-1121. [CrossRef]

31. Eikelenboom, M.; de Jong, G. The impact of dynamic capabilities on the sustainability performance of SMEs. J. Clean. Prod. 2019, 235, 1360-1370. [CrossRef]

32. Stokes, P.; Moore, N.; Brooks, S.; Caulfield, P.; Wells, J.; Wu, Q.; Duan, Y. Explicating dynamic capabilities for corporate sustainability. Euro. Med. J. Bus. 2013, 8, 255-272.

33. Mazzucato, M.; Perez, C. Innovation as Growth Policy: The Challenge for Europe. In The Triple Challenge for Europe: Economic Development, Climate Change and Governance; Fagerberg, J., Laestadius, S., Martin, B.R., Eds.; Oxford University Press: Oxford, UK, 2015; pp. 229-260.

34. Rao, J.; Weintraub, J.R. How innovative is your company's culture? MIT Sloan Mgmt. Rev. 2013, 54, 29.

35. Dutta, S.; Lanvin, B.; Wunsch-Vincent, S. Proceedings of the Global Innovation Index 2020: Who Will Finance Innovation; World Intellectual Property Organization: Geneva, Switzerland, 2020.

36. Aguilar-Barcelo, J.; Higuera-Cota, F. Challenges in innovation management for Latin America and the Caribbean: An efficiency analysis. CEPAL Rev. 2019, 2019, 7-23. [CrossRef]

37. Mazzucato, M.; McPherson, M. The Green New Deal: A Bold, Mission-Oriented Approach; UCL Institute for Innovation and Public Service: London, UK, 2018.

38. Mazzucato, M.; Semieniuk, G.; Watson, J. What Will It Take to Get Us a Green Revolution? Sussex Energy Group Policy Paper: Sussex, UK, 2015.

39. Avila-Lopez, L.A.; Santos Lopez-Leyva, C.L. Innovation and growth: Evidence from Latin American countries. J. Appl. Econ. 2019, 22, 287-303. [CrossRef]

40. Pisano, G.P.; Shih, W.C. Restoring American competitiveness. Harv. Bus Rev. 2009, 87, 114-125. 